$\ldots$

NASA Technical Memorandum 105148

\section{$1 N-39$ \\ 37986}

\title{
Structural Design Concepts for a Multi-Megawatt Solar Electric (SEP) Spacecraft
}

Charles Lawrence and J. Mark Hickman

Lewis Research Center

Cleveland, Ohio

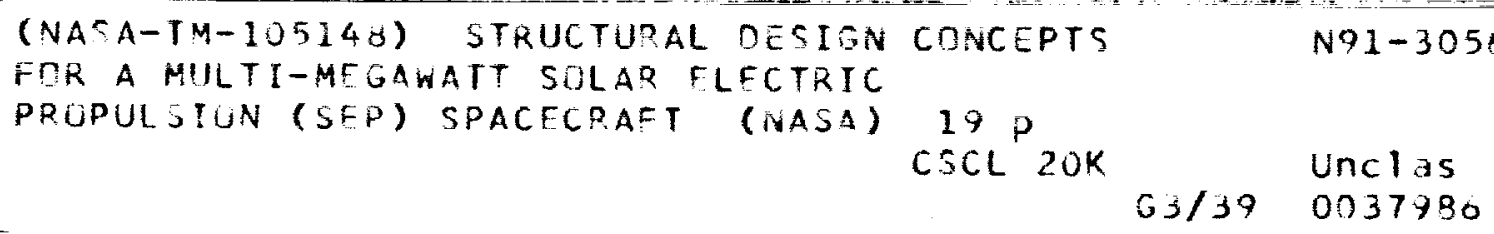

August 1991

\section{N/Sก}

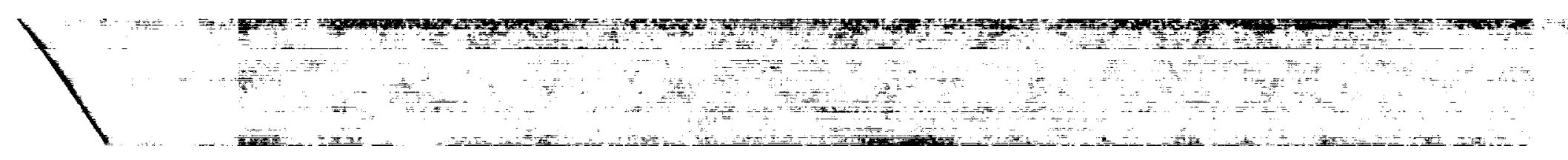




\title{
STRUCTURAL DESIGN CONCEPTS FOR A MULTI-MEGAWATT
}

\section{SOLAR ELECTRIC PROPULSION (SEP) SPACECRAFT}

\author{
Charles Lawrence and J. Mark Hickman \\ National Aeronautics and Space Administration \\ Lewis Research Center \\ Cleveland, Ohio 44135
}

\begin{abstract}
SUMMARY
As a part of the Space Exploratory Initiative (SEI), NASA Lewis Research Center is investigating Solar Electric Propulsion (SEP) spacecraft to be used as a cargo transport vehicle to MARS. The purpose of the present study is to offer two preliminary structural design concepts for the SEP spacecraft; a split blanket array configuration, and a ring structure. The split blanket configuration is an expansion of the photovoltaic solar array design proposed for Space Station Freedom and consists of eight independent solar blankets stretched and supported from a central mast. The ring structural concept is a circular design with the solar blanket stretched inside a ring. This concept utilizes a central mast with guy wires to provide additional support to the ring. The two design concepts are presented, then compared by performing stability, normal modes, and forced response analyses for varying levels of blanket and guy wire preloads. The ring structure configuration is shown to be advantageous because it is much stiffer, more stable, and deflects less under loading than the split blanket concept.
\end{abstract}

\section{INTRODUCTION}

As a part of the Space Exploratory Initiative (SEI), NASA Lewis is investigating scenarios for a mission to MARS. In support of this effort, NASA Lewis is studying a Solar Electric Propulsion (SEP) spacecraft to be used as a cargo transport vehicle to MARS. A Solar powered spacecraft is thought to be advantageous because of low development costs, reliability, minimal propellent requirements, lack of radiation, and the potential to reuse the power system for other applications. Critical spacecraft elements which presently are under study, at Lewis, are spacecraft power and propulsion systems, as well as their accompanying structures (refs. 1 and 2). Structures are particularly important for SEP vehicles because of the very large surface areas which must be supported to accommodate the solar power systems. As a result, the spacecraft structure is very significant and greatly influences the overall spacecraft design and weight.

Several variations of mission profiles are under consideration for the Mars activity. The mission profile which appears most favorable is to originate flight from a space station (e.g., Space Station Freedom) in Low Earth Orbit (LEO) and then proceed to a Mars orbit. Deviations from this plan which also are under consideration are initiating from Geosynchronous orbit or from Low Lunar Orbit (LLO). One way trips, where the spacecraft would be abandoned or used as a power source at Mars, as well as round trip (return to GEO) scenarios where the spacecraft is reused, are under consideration.

Both the payloads and the power requirements for the Mars spacecraft are formidable. Payload masses vary from 100 to 400 metric tones and power requirements are in the 5 to $10 \mathrm{MW}$ range. Round trip flight times vary from 1100 to 1500 days, depending on the flight trajectory, cargo mass, and available power. 
With the significant level of activity involving Space Station Freedom and solar power, substantial advances have been made in photovoltaic solar power technology (refs. 3 and 4). For the Mars spacecraft presently under consideration, multijunction solar cells in a concentrator type configuration appear as the most promising. The multijunction cells provide higher efficiencies ( 25 to 30 percent) by utilizing layers of cells, each capable of absorbing different spectral bands of solar energy. Additional efficiency also is obtained by utilizing a concentration scheme where solar radiation is reflected from a primary parabolic reflector to a secondary hyperbolic reflector and then, finally, to the solar cells. The overall concentrator panel thickness is no thicker than that of conventional solar panels. Power density is projected to reach $300 \mathrm{~W} / \mathrm{M}^{2}$ of solar blanket surface area. Clearly high density levels are desirable for minimizing the required blanket area and accompanying support structure size and weight.

In addition to supporting the solar blanket, the spacecraft structure will be used to sustain the cargo and provide appendages for the thrusters used for propulsion. As with previous spacecraft, the structure will be designed to meet stress and stiffness requirements with, obviously, the overall design objective being minimum weight. In contrast to previous spacecraft structural designs, the present structural designs will be influenced more by stiffness requirements, whereas previous designs often have been dictated by stress limitations. In the past, the most severe loads the spacecraft, which was entirely constructed on earth, was exposed to were a result of the launch environment. On orbit loading was significantly less demanding on the spacecraft. With present spacecraft such as Space Station Freedom and SEP, the spacecraft will be deployed or constructed in space, and the loading situations will be considerably more complex. While the structural integrity of the packaged spacecraft components may be most influenced by the launch situation, the completed spacecraft will be effected only by on-orbit (or in flight) loadings. Furthermore, since the loadings in space generally are very small, stiffness rather than stress limitations probably will dominate the structural design. Also, since the structure will be so light and flexible, small loadings, such as an astronaut bumping into a structural element, will have the potential to incur considerable damage.

Actual construction of the SEP will present another challenging problem. Because of the SEP's large size, unique construction methods will need to be devised. The structure may be constructed by exacting deployment schemes, by in space erection methods, or most probably, by a combination of both. No matter which methods are selected, they will be complex. To gain perspective, Space Station Freedom is the largest spacecraft ever to be placed in space and it still is only in the design stage. The SEP may be more than twenty times as large and massive as Space Station Freedom.

The purpose of the present study is to present two preliminary structural design concepts for the Solar Electric Propulsion (SEP) spacecraft for a mission to Mars; a split blanket array configuration, and a ring structure. Both designs are described in subsequent sections, then assessed by comparing their overall weights, stiffnesses, and performance under loadings.

Although Space Station Freedom has spawned considerable work related to space structures, the existence of studies which provide potential structural configurations meeting very large spacecraft requirements remain very limited. In reference 5 general design guidelines for large space structures are provided with an overview of operational loads as well as structural requirements and design examples. In reference 6 concepts and erection methods for large space trusses are presented. Reference 7 discusses construction in space and some novel structural systems such as centrifugal structures. References 8 to 10 address issues related to deployment, erection, strength, and dynamics of large space structure trusses while reference 11 addresses design 
concepts for military applications. References 12 to 17 provide conceptual studies for large solar reflectors, solar concentrators, and infrared telescopes. The structural aspects of these spacecraft are emphasized.

\section{STRUCTURAL CONCEPTS}

The first structural concept (ref. 18) is based on an segmented octagonal split blanket configuration. The main components of each octagonal segment are a central mast for supporting thrusters and upper and lower cross booms. Split blanket arrays are stretched between the cross booms (fig. 1). This configuration is similar to previously developed designs such as the Space Station Freedom Photovoltaic Solar Arrays. The major difference between previous designs and the present array is that the present design is considerably larger and the cross booms are of unequal length. As a result, the present design has nonrectangular solar blankets, while the Space Station will use rectangular blankets. Deployment of the proposed configuration, as in the case of the Space Station Freedom arrays, could be accomplished by extending the central mast, unfolding the booms from the mast, and then stretching out and tensioning the blankets. The second structural concept is based on a circular design proposed in reference 17 for very large solar concentrators (fig. 2). Although this design was originally intended for a $1 \mathrm{~km}$ diameter solar reflector for illuminating earth stations, it is equally qualified for the present application. The design consists of a central mast which extends perpendicular to the solar blankets and an outer ring truss structure suspended by guy wires. The solar blanket is stretched inside the ring truss.

Both structural concepts employ a $200 \mathrm{M}$ mast extension for mounting thrusters. The thrusters are located at this distance to maximize their ability to control the spacecraft orientation and to minimize plume impingement on the arrays. The disadvantage of mounting the thrusters on long booms is that the structure must be made strong enough to withstand the bending moment due to the long cantilever.

Deployment of the split blanket array configuration is simplified because the spacecraft is segmented into eight independent arrays, each of which may be independently stowed, launched, and deployed. Using an assumed blanket thickness of $3 \mathrm{~cm}$ and assuming the structure is 15 percent of the total system volume, an array total volume would be $220 \mathrm{M}^{2}$. With proper packaging the volume of one, and possibly two, arrays could fit in Shuttle-C. All eight arrays could fit in Advance Launch System (ALS). Deployment of the ring design is considerably more complex than for the split blanket design. Although rather complex, deployment feasibility has at least been demonstrated in theory for the solar reflector concept. Deployment problems could be encountered because of the difficulties associated with the irregular fold required in the solar blankets (the reflector substrate was only several mils thick while the present blanket thickness is near $3 \mathrm{~cm}$ ). Another problem is that the design is not segmented and its total volume $\left(1800 \mathrm{M}^{2}\right)$ would require a vehicle with the capacity of ALS. Segmenting the design may permit it to conform to smaller launch vehicles, however integrating the components in space could require considerable astronaut activity.

A preliminary weight comparison among the two design concepts and the planned Space Station is shown in table I. The estimated specific power for these concepts were obtained from previously performed studies (refs. 4 and 19). Although these estimates were derived for earth orbiting spacecraft, the values appear reasonable since the spacecraft structures undergo their critical loadings during earth orbit. The specific power and array areas were used to compute 
total spacecraft weights. Actual preliminary design values appear for Space Station Freedom. As shown in the table both the split blanket and ring designs are considerably lighter than the Space Station Freedom arrays. The Mars spacecraft concepts are lighter than Space Station Freedom because of utilization of advanced solar technologies and the potential to reduce unit weights with very large structures. (Structural weight/size tends to decrease with size.)

For the present study, it is assumed that the ring and split blanket structures have identical specific powers. As a result, the structures have identical weights. Since both structures weigh the same, and the segmented octagon is not as structurally efficient as the ring, the octagon design is more flexible. The suspended ring is stiffer than the segmented octagon because the ring structure is primarily a tension-compression system while the segmented octagon is a bending type structure. The ring structure obtains much of it's stiffness from the guy wires, which are relatively light, while the segmented octagon acquires it's stiffness in the form of bending resistance obtained from it's masts. For the segmented octagon to be as stiff as the ring structure the central mast would be required to be relatively large and therefore heavy. Since both structures weigh the same, the segmented octagon is more flexible.

\section{STRUCTURAL MEMBER SIZING}

An estimate of the structural member properties is required to generate structural models of the SEP spacecraft. The member properties are required so that the mass and stiffness distribution of the structure may be characterized for the model and subsequent analyses. To determine the structural element's characteristics, namely mass and cross sectional properties, an approximate relationship between mass, cross sectional area, and area moment of inertias, was derived.

Figure 3 shows a cross section of a possible SEP structural element. The section is assumed to be doubly symmetric with the bulk of the areas concentrated at the corners so as to maximize the area moments of inertia. The corner areas may be supported by thin webs, or for larger cross sections by truss elements. The main function of the web is to develop the full potentials of the cross section without incurring instability problems.

The area moment of inertia of the cross section is approximately equal to:

$$
I=1 / 4 A a^{2}+2 / 3 t a^{3}
$$

where $\mathrm{I}$ is the area moment of inertial, $\mathrm{A}$ is the total area of the four corners, $\mathrm{a}$ is the height or width of the section, and $t$ is the effective web thickness.

The total area of the section is:

$$
\mathrm{A}_{\mathrm{T}}=\mathrm{A}+4 \mathrm{at}
$$

Assuming larger cross sections will require more web support, a ratio between $a$ and $t$ is defined as:

$$
\mathbf{a} / \mathbf{t}=\mathbf{g}
$$


Substituting (3) into (1) and (2):

$$
I=1 / 4 A g^{2} t^{2}+2 / 3 g^{3} t^{4}
$$

and

$$
\mathbf{A}_{\mathrm{T}}=\mathrm{A}+4 \mathrm{~g} \mathrm{t}^{2}
$$

The objective is to find a relation between the corner area, $\mathbf{A}$, and the area moment of inertia, I. Since equations (4) and (5) contain three unknowns $\left(A, A_{T}\right.$, and $t, I$ is specified), an objective function which minimizes area is used to solve for the third variable.

The objective function containing the cross sectional area and moment of inertia constraint is:

$$
\mathrm{J}=\mathrm{A}+4 \mathrm{~g} \mathrm{t}^{2}+\lambda\left[1 / 4 \mathrm{~A} \mathrm{~g}^{2} \mathrm{t}^{2}+2 / 3 \mathrm{~g}^{3} \mathrm{t}^{4}-\mathrm{I}_{\mathrm{req}}\right]
$$

Where $\lambda$ is a Lagrange multiplier. Taking the partial derivative of (6) with respect to thickness, $t$, and corner area, $A$, then setting both derivatives to zero yields:

$$
\begin{gathered}
\mathrm{t}=\left(\mathrm{I}_{\mathrm{req}} / \mathrm{g}^{3}\right)^{1 / 4} \\
\text { and } \\
\mathrm{A}_{\mathrm{T}}=5.3 \mathrm{~g}^{-1 / 2}\left(\mathrm{I}_{\mathrm{req}}\right)^{1 / 2}
\end{gathered}
$$

For $a / t=200, A_{T}$ is approximated by:

$$
A_{\mathrm{T}}=.375\left(\mathrm{I}_{\mathrm{req}}\right)^{1 / 2}
$$

Assuming a specific power of $150 \mathrm{~W} / \mathrm{kg}$ (table I) and that 15 percent (an approximation) of the weight is attributed to the structural elements, then, for a $10 \mathrm{MW}$ spacecraft the available structural weight would be $10000 \mathrm{~kg}$. For the split blanket configuration, having $\mathbf{3 2 5} \mathrm{m}$ of element length in each of eight arrays (fig. 1), the resulting element unit weight is $3.8 \mathrm{~kg} / \mathrm{m}$. For the ring structure, which has a total element length of $1670 \mathrm{~m}$ (fig. 2) the element unit weight is $6.0 \mathrm{~kg} / \mathrm{m}$. From the unit weights and equation $8(\mathrm{~b})$ the available cross sectional inertias are computed.

Figure 4 and table II show the frequencies and stiffness ratios for various structural elements including the SEP. The purpose of this figure and table is to provide a "feel" for the relative stiffness and weight of various structural designs. The frequency to weight ratio gives an overall idea of the element's performance. To maintain an equal comparison, the frequencies were computed by cantilevering an unloaded $100 \mathrm{ft}$ length of element rather than using the frequencies of the spacecraft where the elements are actually used. While table II provides a direct comparison of the element's stiffness ratios, figure 4 displays the absolute stiffness values. The Space Station Freedom main truss element is the least efficient with a ratio of only 0.049 while the TRW element is most efficient at 0.694 (The TRW element was taken from a conceptual design for a multikilowatt solar array.) The SEP structural element's ratio lie between at 0.061 and 0.085 . The SEP ring structural element is slightly heavier and stiffer than the split blanket because since the ring design does not require as much linear length of element, 
and both spacecraft are of equal weight, more of the total weight is allocated to each unit length of element for the ring structure. Along with the increase in unit weight there is also an increase in stiffness since the element cross section has a larger moment of inertia. It should be pointed out that the SEP elements utilize a very conservative modulus of elasticity (equivalent to aluminum) while the other elements have moduli based on more aggressive materials.

\section{STRUCTURAL MODELLING}

Three versions of models were generated for each of the split blanket and ring structure designs; (1) a geometric nonlinear version for incorporating array blanket prestress, (2) a modal version for computing free vibrations, and (3) a modal forced response version.

The geometric nonlinear model is required so that the effects of blanket and guy wire prestress may be established. The preloading is required to provide blanket stiffness and stability for the outer ring in the ring structure. The modal model is used to calculate the structure's free vibration frequencies, mode shapes, and stiffness characteristics. Finally, the forced response model is used to predict structural response resulting from in-service loadings such as thruster firing. The finite element computer program, MSC/NASTRAN (ref. 20), was used to generate finite element models of both the split blanket and ring structures. NASTRAN Solution Sequences 64, 63, and 72 were used for the geometric nonlinear, modal, and modal transient analyses, respectively.

The finite element model for the split blanket model (fig. 5) consists of 79 grid points (474 degrees of freedom) and 101 elements. For this model it is assumed that the cargo mass is large enough so that it provides a "fixed" boundary condition for each of the eight split blankets. (The arrays only are connected at their bases) Using this assumption, along with symmetry, it is necessary to model only one of the eight arrays. The array blanket is constructed from plate elements with in-plane elastic membrane and out-of-plane geometric stiffnesses. The blanket is attached at it's top and bottom to cross beams which are supported off of a central mast, also constructed of beam elements. The central mast is extended outward to support thrusters. The thrusters are modeled as concentrated masses. The mast extension is stiffened by preloaded guy wires on either side. The blanket preload is incorporated by applying equal and opposite loadings to the ends of the blanket and cross beams.

The finite element model for the ring structure (fig. 2) consists of 447 grid points (2682 degrees of freedom) and 430 elements. Similarly to the split blanket model, it is assumed that the center ring is "fixed" as a result of the relatively large cargo mass. However, unlike the split blanket structure, the ring structure model does not utilize symmetry. Instead, the entire structure is included in the finite element model. Similarly to the split blanket model, the array blanket is constructed from plate elements dominated by elastic membrane and geometric stiffness. The blanket is attached at it's outer and inner edges to circular ring beams which are supported out of plane by guy wires. The guy wires are attached to a central mast which extends above and below the array surfaces. Extending from eight equally spaced locations on the outer ring beam are beam extensions which support the thrusters. The thrusters, as with the split blanket model, are located $200 \mathrm{M}$ from the center of the spacecraft, and are modeled as concentrated masses. Preload is applied to the guy wires by applying a loading at the top and bottom of the central mast which increases the lateral stability of the outer ring beam by simultaneously stretching the wires. The central mast is loaded in compression. Preload is applied to the blanket and outer ring beam by applying equal and opposite loads where the 
array blanket attaches to the outer ring beam. Basically, the guy wire and blanket preloads act independently, with the blanket preload causing in-plane buckling of the outer ring and the guy wire preload providing in-plane and out-of-plane ring stiffness.

\section{STRUCTURAL STABILITY AND MODAL CHARACTERISTICS}

To determine the structural stability and modal characteristics of the SEP spacecraft structures, varying levels and combinations of preload where applied. The preload was increased until the structures became unstable. During the geometrically nonlinear analysis, which provides an iterative method to ascertain stability, a linear elastic analysis is performed to determine an initial state of loadings. The loads then are used to compute the increase, or reduction, in the member stiffnesses resulting from the preload. The loadings are recomputed and the procedure is repeated until convergence is reached. Instabilities are identified when the global stiffness matrix is no longer positive definite. For stable configurations, the mass and stiffness matrices resulting from the geometric nonlinear analysis are used in the subsequent modal analysis to compute the structure's characteristic frequencies and mode shapes. The geometric stiffness is assumed to remain constant throughout the transient response.

The split blanket array preloading has multiple effects. First, the preload on the blanket, which as mentioned has negligible out of plane elastic stiffness, provides a primary stiffening effect. This in turn provides a mechanism for increasing the blanket's natural frequencies. Second, since the preload does not produce completely uniform blanket stresses, there exist local areas of compression in the blanket which cause local blanket buckling. However, since these areas of instability are local, they may be neglected so far as overall structural stability is concerned. Third, the blanket preload is transmitted through the top and bottom cross beams then into the central mast. This compresses the mast, which for high enough loading, causes buckling.

Figures 6 and 7 show the split blanket frequencies and mode shapes for varying levels of preload. As expected, without any preload $\left(P / P_{c r}=0\right.$.), the blanket frequencies are near zero because the blanket has minimal stiffness in the absence of preload. As the preload is increased, the natural frequencies also increase due to the added stiffening effects. Near the mast buckling load $\left(\mathrm{P} / \mathrm{P}_{\mathrm{cr}}=1\right.$.) the first modal frequency decreases to zero due to the buckling of the mast. At this point the structure is unable to tolerate any additional loadings and the preloading actually has a destabilizing effect. The first 6 system mode shapes (fig. 7) are displayed for a preload of $\mathrm{P} / \mathrm{P}_{\mathrm{cr}}=0.9$.

The ring structure preloading scheme also has multiple effects. As with the split blanket, the blanket preload provides the mechanism for increasing the blanket's natural frequencies as well as a source for in-plane compression in the blanket, the outer ring beam, and the central mast. Figure 8 describes the effect of various combinations of guy wire and blanket preloads. As shown in the figure, increasing the blanket preload has a stabilizing effect on the blanket up to $0.30 \mathrm{P}_{\text {cr ring }}$ where local instabilities occur in the blanket. Above $0.03 \mathrm{P}_{\text {cr ring }}$, and without guy wire tension, the blanket preload causes the outer ring to buckle. The guy wire preload has a stabilizing effect on the outer ring, but above $\mathrm{P}_{\mathrm{cr} \text { mast }}$ causes the mast to buckle. Fortunately, it is only required to apply a small amount of guy wire preload to stabilize the outer ring from out-of-plane buckling, and any additional guy wire preload is unnecessary. Additional guy wire preload is not beneficial because with out-of-plane support the ring will buckle in-plane where 
the guy wires do not provide support. Note that a blanket preload of $0.30 \mathrm{P}_{\text {cr ring }}$ corresponds to a blanket tension of approximately $60 \mathrm{~N} / \mathrm{M}(4 \mathrm{lb} / \mathrm{ft})$.

Figures 9 and 10 show the modal frequencies and mode shapes of the ring structure in the ranges of preloading where the structure is stable. This data, which was generated for the first four modes for different levels of blanket and guy wire preload, shows the effect of various combinations of preloadings. For the first two modes, which are identical but $90^{\circ}$ out of phase from each other, both the blanket and guy wire preloads have destabilizing effects. This effect is best explained as a result of the preload softening effect in the outer ring and central masts being greater than the stiffening effects in the blanket. The third and fourth modes are dominated by blanket deflections, with minimal motions in the ring and masts, and are therefore stiffened by the preloadings. Figures $9(\mathrm{~b})$ and (c) shows the overall stiffening of the modal frequencies as a function of preload.

\section{MODAL TRANSIENT RESPONSE}

Loading conditions are most severe when the spacecraft is at low earth altitudes, spiralling outward. During this portion of the trajectory the spacecraft is exposed to gravity gradient, atmospheric drag, solar pressure, and thruster firings. By far, thruster firing generates the dominating loadings. Thruster firing is orders of magnitudes greater than the other three loadings, and therefore, will be the only force used for the transient response predictions.

At low altitudes, earth orbit takes approximately $90 \mathrm{~min}$ to complete. For a little less than half of this time ( $<45 \mathrm{~min}$ ) the spacecraft is shadowed from the sun and the thrusters are powerless and do not produce loads. For the other period the thrusters are at full power and generating loading. (Battery systems have been considered to keep the thrusters operating throughout the entire orbit, but they have proven inefficient due to their large weight.) For the $10 \mathrm{MWe}$ spacecraft considered in this study, each of the 8 thrusters produces $34.5 \mathrm{~N}$ of thrust during their on period.

For the modal transient analysis the first twelve systems modes and $1 / 2$ percent modal damping were used. These modes were generated at a blanket preload of $0.11 \mathrm{P}_{\mathrm{cr}}$ ring and a guy wire load of $0.005 \mathrm{P}_{\mathrm{cr} \text { mast }}$ for the ring structure, and at $0.2 \mathrm{P}_{\mathrm{cr}}$ for the split blanket. It was assumed that all eight thrusters would be operated in phase (all off or all on) and that the thruster loading would be applied as a step function. In reality phasing of the thruster firings may be necessary to keep the spacecraft pointed towards the sun. However, for a first order evaluation the present loading formation is sufficient.

Figures 11(a) and (b) show a side view of deflected shapes resulting from the thruster loadings for the ring structure and split blanket configurations, respectively. While the actual displacement response resulting from the loadings is oscillatory, A snapshot of the response, taken when the thruster deflection is at it's peak response, is shown in the figures. The complete response, obviously, is oscillatory and decays considerably, as a result of damping, between shadow and illuminated periods.

By comparing the deflected shapes (drawn full scale) between the ring and split blanket systems, it is clear that the ring structure is considerably stiffer and therefore more capable of accommodating the thruster loadings. Due to the guy wire support of the outer ring, the ring structure blanket undergoes very little deformation, while the thruster extension exhibits 
reasonable deflections because of it's relatively short (70M) cantilever length. The split blanket configuration, on the other hand, exhibits very large deflections because it has no out of plane support and it's effective cantilever length is the full 200M. The modal frequencies (figs. 6 and 9) of the two configurations also are reflective of their relative stiffnesses, and the split blankets ineffectiveness to sustain out-of-plane loads. Note that for either structure, the stresses are within allowable limits.

\section{CONCLUDING REMARKS}

As shown in this study, the ring structure configuration has several advantages over the split blanket structure. For a fixed quantity of available structure, the ring structure is orders of magnitude stiffer, it is more stable as a result of shorter compression members, and it deflects less and has less stress as a result of operating loadings. The only identified disadvantage of the ring configuration is that it may be more difficult to deploy or construct in space.

\section{REFERENCES}

1. Hickman, J.M., et al.: Solar Electric Propulsion For Mars Transport Vehicles, NASA TM-103234, 1990.

2. Hickman, J.M., et al.: Systems Analysis of Mars Solar Electric Propulsion Vehicles, AIAA Paper 90-3824, Sept. 1990.

3. Piszczor, M.F., et al.: The Mini-Dome Fresnel Lens Photovoltaic Concentrator Array: Current Status Of Component \& Prototype Panel Testing. 21st Photovoltaic Specialists Conference, Vol. 2, IEEE, 1990, pp. 1271-1776.

4. Patterson, R.E.: Study of Multi-Kilowatt Solar Arrays for Earth Orbit Applications. (REPT-38172-6001-UE-00, TRW Space Technology Labs; NASA Contract NAS8-34131), NASA CR-170939, 1983.

5. Hedgepeth, J.M.: Critical Requirements for the Design of Large Space Structures. NASA CR-3484, 1981.

6. Brahney, J.H.: Structural Concepts For Future Space Systems. Aerospace Eng., vol. 8, no. 12 , Dec. 1988 , pp. 10-14.

7. Gvamichava, A.S.; and Koshelev, V.A.: Construction in Space. NASA TM-77630, 1984.

8. Bush, H.G., et al.: Deployable and Erectable Concepts for Large Spacecraft, NASA TM-81904, 1980.

9. Mikulas, M.M., Jr.: In-Space Construction and Dynamics of Large Space Structures. Space Vehicle Flight Mechanics, AGARD CP-489, 1990, pp. 26-1 to 26-10.

10. Mikulas, M.M., Jr.; Bush, H.G.; and Card, M.F.: Structural Stiffness, Strength and Dynamic Characteristics of Large Tetrahedral Space Truss Structures. NASA TM-74001, 1977. 
11. Eubanks, R.A.; and Smith, A.: Investigation of Design Concepts for Large Space Structures to Support Military Applications. CERL-TR-M-87/16, Sept. 1987 (Avail NTIS, ADA186098).

12. Mikulas, M.M., Jr.; and Hedgepeth, J.M.: Structural Concepts for Very Large (400-MeterDiameter) Solar Concentrators. Second Beamed Space Power Workshop, R.J. DeYoung, ed., NASA CP-3037, 1989, pp. 239-257.

13. Hedgepeth, J.M.: Support Structures for Large Infrared Telescopes. NASA CR-3800, 1984.

14. Mikulas, M.M., Jr.; Collins, T.J.; and Hedgepeth, J.M.: Preliminary Design Approach for Large High Precision Segmented Reflectors. NASA TM-102605, 1990.

15. Hedgepeth, J.M.; and Miller, R.K.: Structural Concepts for Large Solar Concentrators. NASA CR-4075, 1987.

16. Canady, J.E., Jr.; and Allen, J.L., Jr.: Illuminating From Space With Orbiting SolarReflector Spacecraft. NASA TP-2065, 1982.

17. Hedgepeth, J.M.; Miller,R.K.; and Knapp, K.P.W.: Conceptual Design Studies for Large Free-Flying Solar-Reflector Spacecraft. NASA CR-3438, 1981.

18. Proposal for Space Station Program WP-04, Solar Array Assemblies, Option One, Vol. 1, LMSC-F177627, Lockheed Missiles and Space Co., Sunnyvale, CA, 1987.

19. Advance Photovoltaic Solar Array Design. (TRW-46810-6004-UT-00, TRW Space Technology Labs; NASA Contract NAS7-918), JPL-9950-1317, NASA CR-186345, 1986.

20. Joseph, J.A., ed., MSC/NASTRAN Application Manual. MacNeal-Schwendler, 1981. 
TABLE I. - SOLAR ARRAY COMPARISONS

\begin{tabular}{|l|c|c|c|c|c|c|}
\hline & Power & $\begin{array}{c}\text { Array } \\
\text { area, } \\
\mathrm{m}^{2}\end{array}$ & $\begin{array}{c}\text { Total array } \\
\text { weight, } \\
\mathrm{kg}\end{array}$ & $\begin{array}{c}\text { Specific } \\
\text { power, } \\
\mathrm{W} / \mathrm{kg}\end{array}$ & $\begin{array}{c}\text { Power } \\
\text { density, } \\
\mathrm{W} / \mathrm{m}^{2}\end{array}$ & $\begin{array}{c}\text { Specific } \\
\text { weight, } \\
\left(\mathrm{kg} / \mathrm{m}^{2}\right)\end{array}$ \\
\hline $\begin{array}{l}\text { Space } \\
\text { Station } \\
\text { Freedom }\end{array}$ & $\begin{array}{c}75 \mathrm{kWe} \\
(8 \text { arrays })\end{array}$ & $\begin{array}{c}800 \times 8 \\
(2400)\end{array}$ & $\begin{array}{c}760 \times 8 \\
(6080)\end{array}$ & 12 & 31 & 2.5 \\
\hline $\begin{array}{l}\text { SEP Mars } \\
\text { Spacecraft } \\
\text { (segmented } \\
\text { octagon) }\end{array}$ & $\begin{array}{c}10 \mathrm{MWe} \\
(8 \text { arrays })\end{array}$ & $\begin{array}{c}6250 \times 8 \\
(50000)\end{array}$ & $\begin{array}{l}8300 \times 8 \\
(67000)\end{array}$ & 150 & 200 & 1.3 \\
\hline $\begin{array}{l}\text { SEP Mars } \\
\text { Spacecraft } \\
\text { (suspended } \\
\text { ring truss) }\end{array}$ & $10 \mathrm{MWe}$ & 50000 & $(67000)$ & 150 & 200 & 1.3 \\
\hline
\end{tabular}

TABLE II. - COMPARSION OF STRUCTURAL ELEMENTS

\begin{tabular}{|l|c|c|c|}
\hline & Frequency $^{\mathrm{a}}$ & Weight & $\begin{array}{c}\text { Ratio (freqency/ } \\
\text { weight) }\end{array}$ \\
\hline $\begin{array}{l}\text { Space Station Freedom } \\
\text { main truss }\end{array}$ & $3 \mathrm{H}_{3}$ & $61.5 \mathrm{~kg} / \mathrm{m}$ & 0.049 \\
\hline $\begin{array}{l}\text { Space Station Freedom } \\
\text { photovoltaic mast }\end{array}$ & 0.56 & 2.06 & 0.272 \\
\hline $\begin{array}{l}\text { SEP, split blanket } \\
\text { elements }\end{array}$ & 0.32 & 3.75 & 0.085 \\
\hline SEP, ring elements & 0.37 & 6.08 & 0.061 \\
\hline $\begin{array}{l}\text { TRW multikilowatt } \\
\text { beam array }\end{array}$ & 0.25 & 0.36 & 0.694 \\
\hline
\end{tabular}

${ }^{\mathrm{a}} 100 \mathrm{ft}$ cantilever length. 

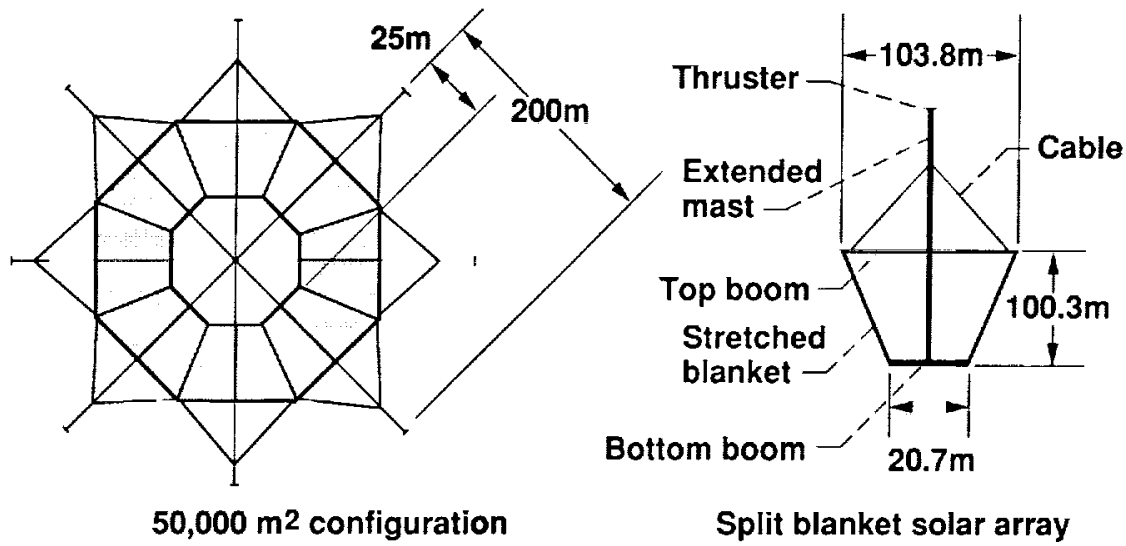

\section{Split blanket solar array} (8 required)

Figure 1.-10 MWe Solar Electric Propulsion (SEP) split blanket structure.

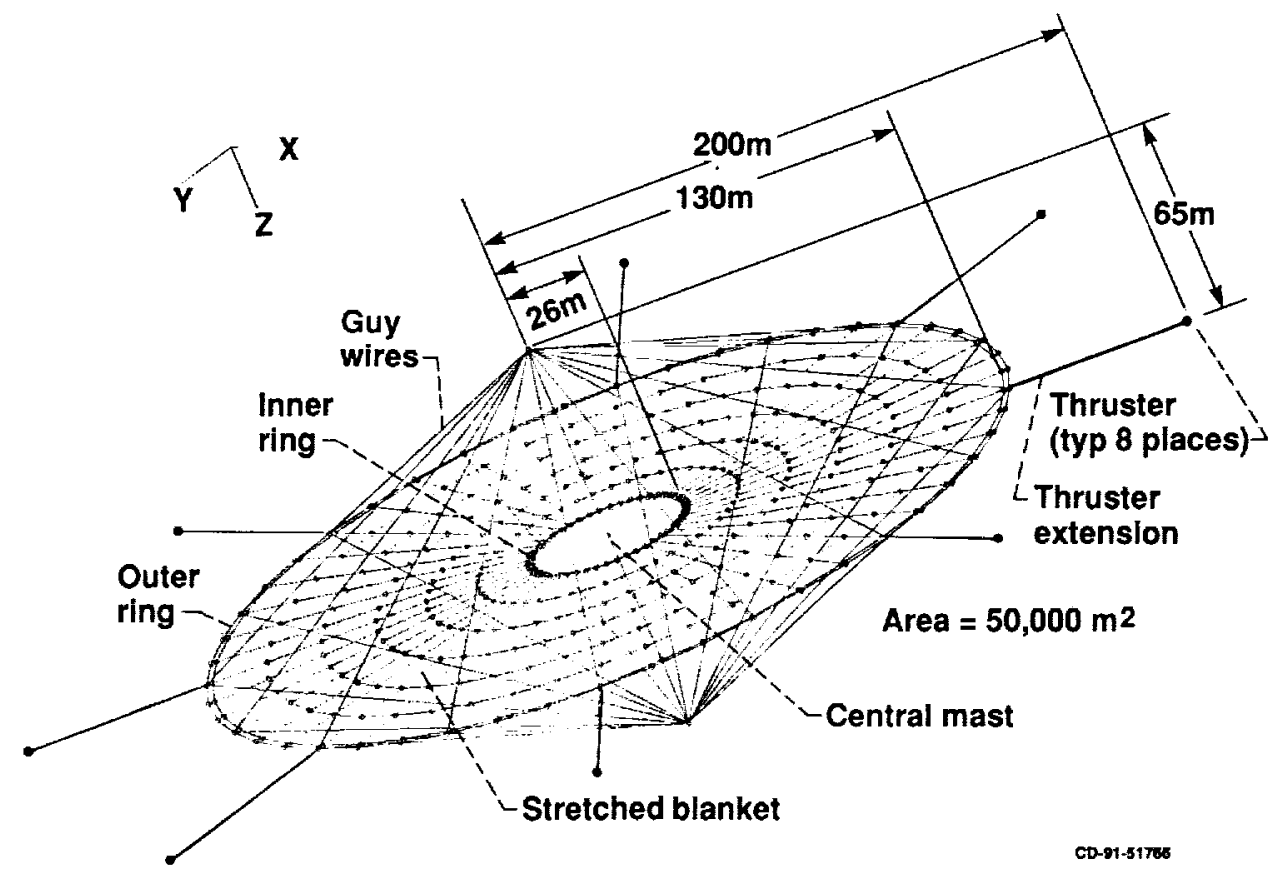

Figure 2.-10 MWe Solar Electric Propulsion (SEP) ring structure. 


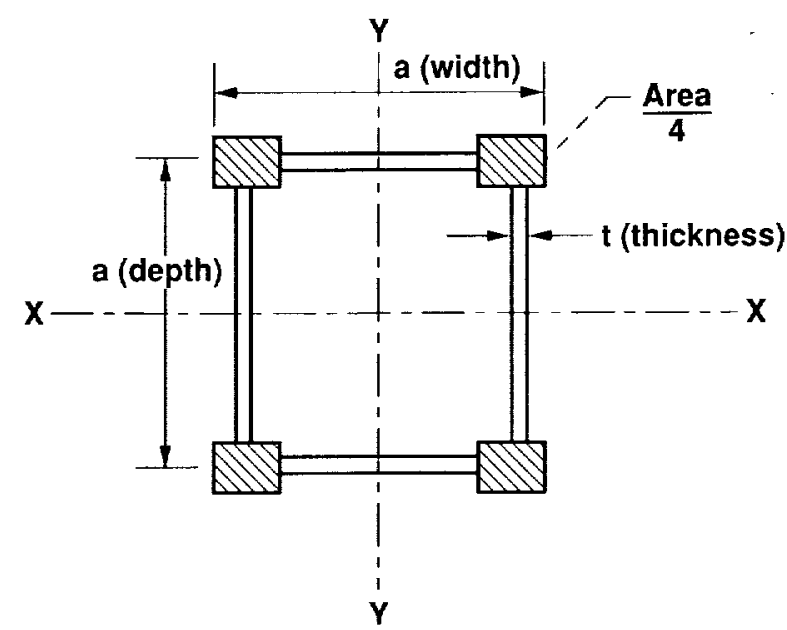

Figure 3.-SEP typical structural element cross section.

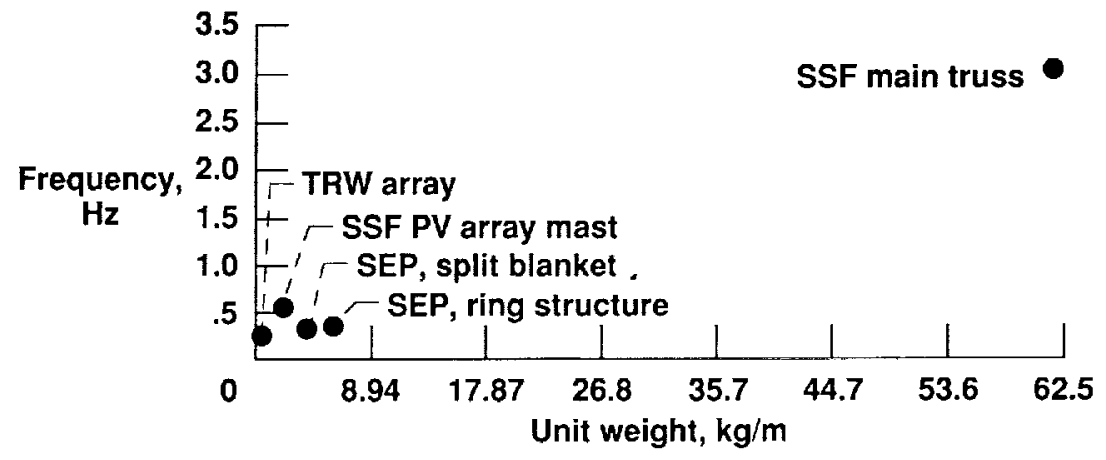

Figure 4.-Representative structural elements; frequency versus unit weight.

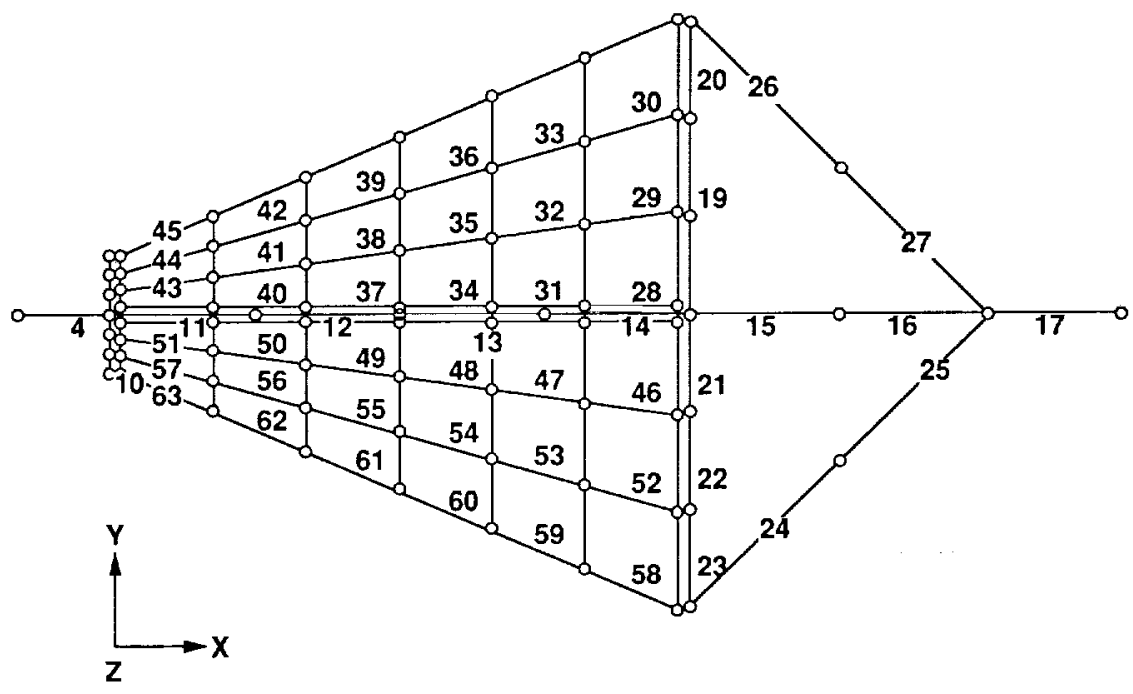

Figure 5.-Split blanket structure finite element model. 


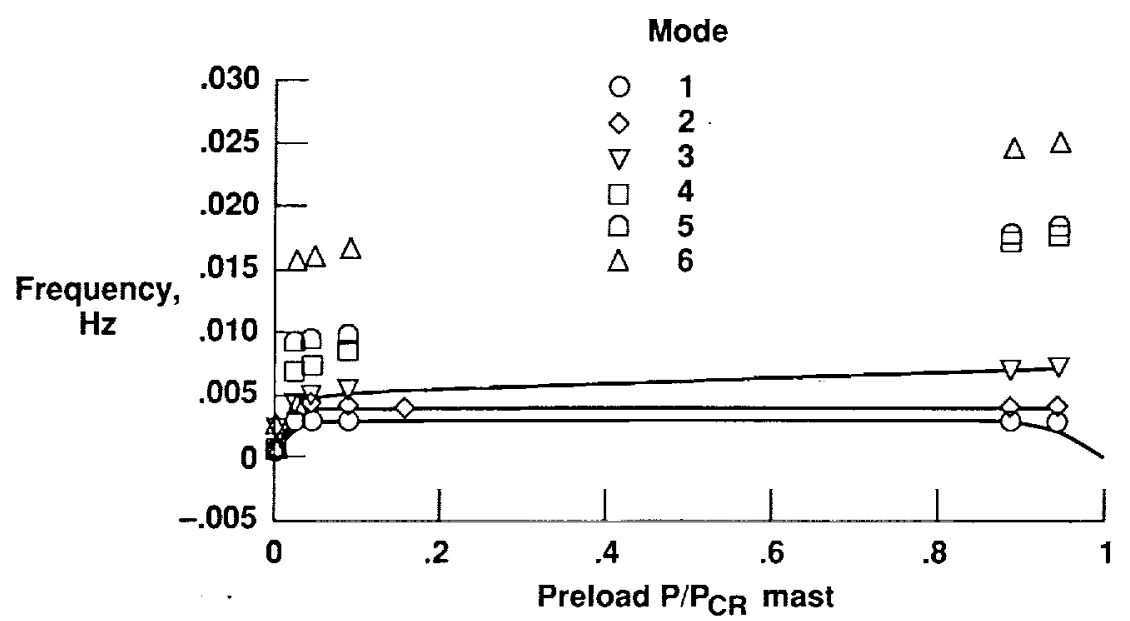

Figure 6.-Split blanket structure; frequency versus preload.

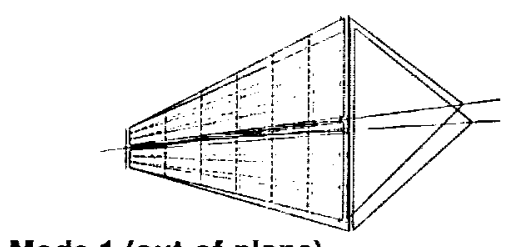

Mode 1 (out-of-plane)

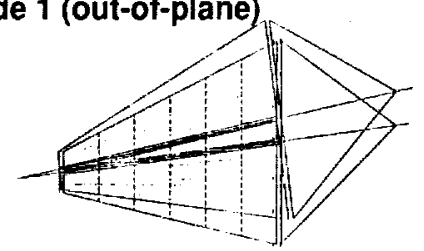

Mode 2 (in-plane)

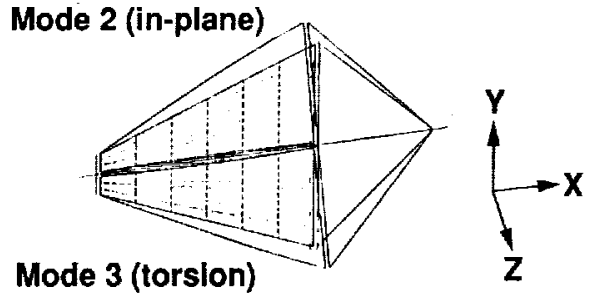

Mode 5 (blanket)

Mode 4 (blanket)
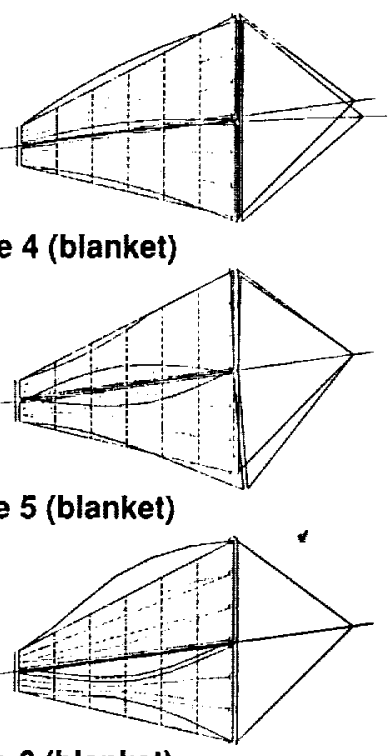

Mode 6 (blanket)

Figure 7.-Split blanket structure mode shapes (preload $=0.9 P_{C R}$ ). 


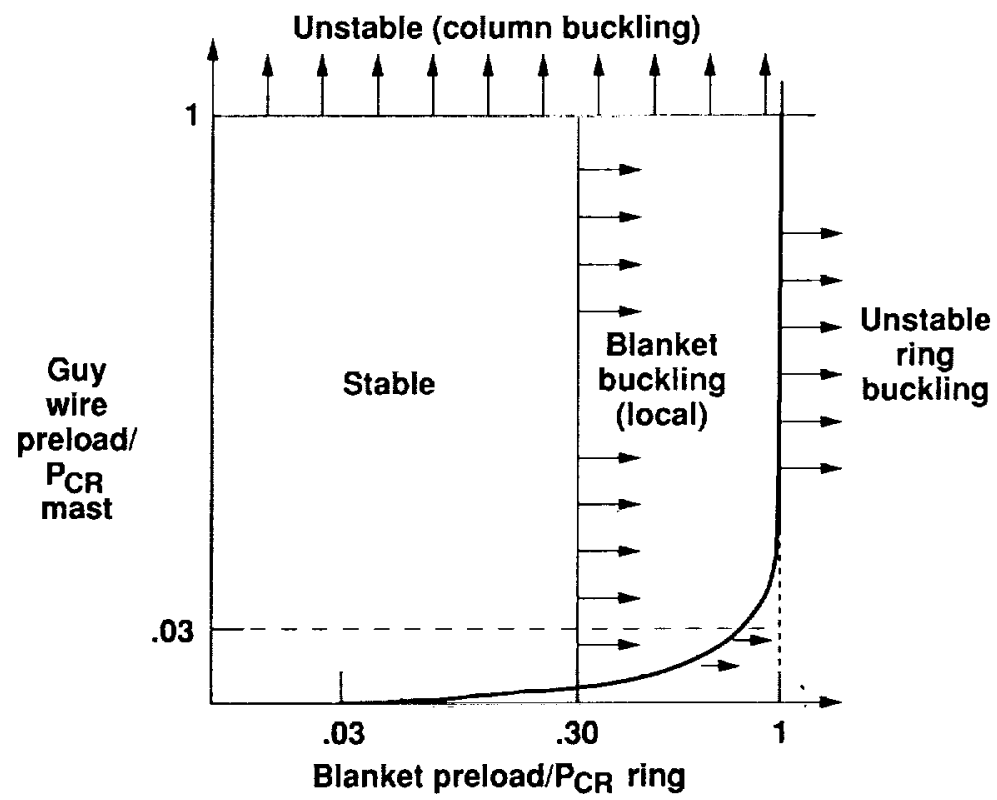

Figure 8.-Ring structure stability diagram.
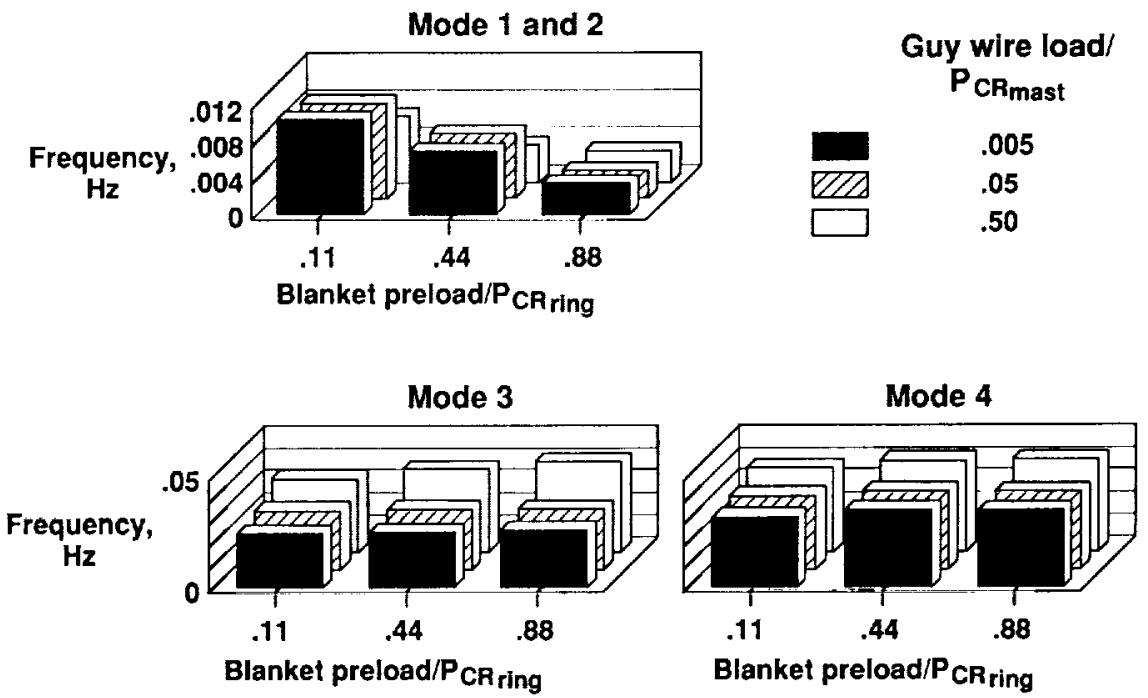

Figure 9.-Ring structure effect of preload on natural frequencies. 


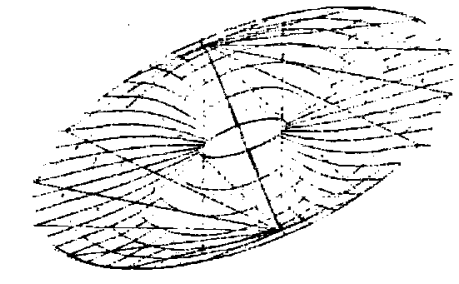

Mode 1 (blanket support mode)

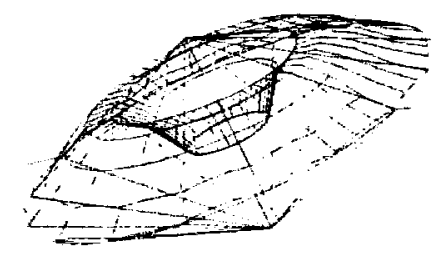

Mode 3 (blanket mode)

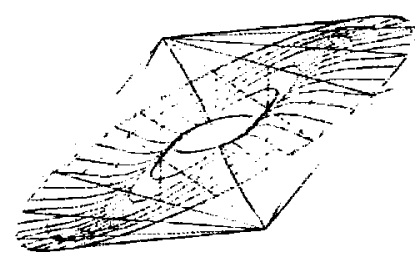

Mode 2 (blanket support mode)

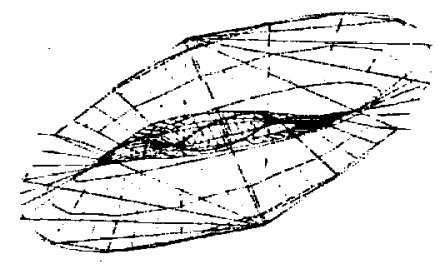

Mode 4 (blanket mode) Figure $10 .-$ Ring structure mode shapes; blanket preload $=0.11 \mathrm{P}_{\mathrm{CR}}$ ring guy
wire preload $=0.005 \mathrm{P}_{\mathrm{CR}}$ mast $^{*}$ 


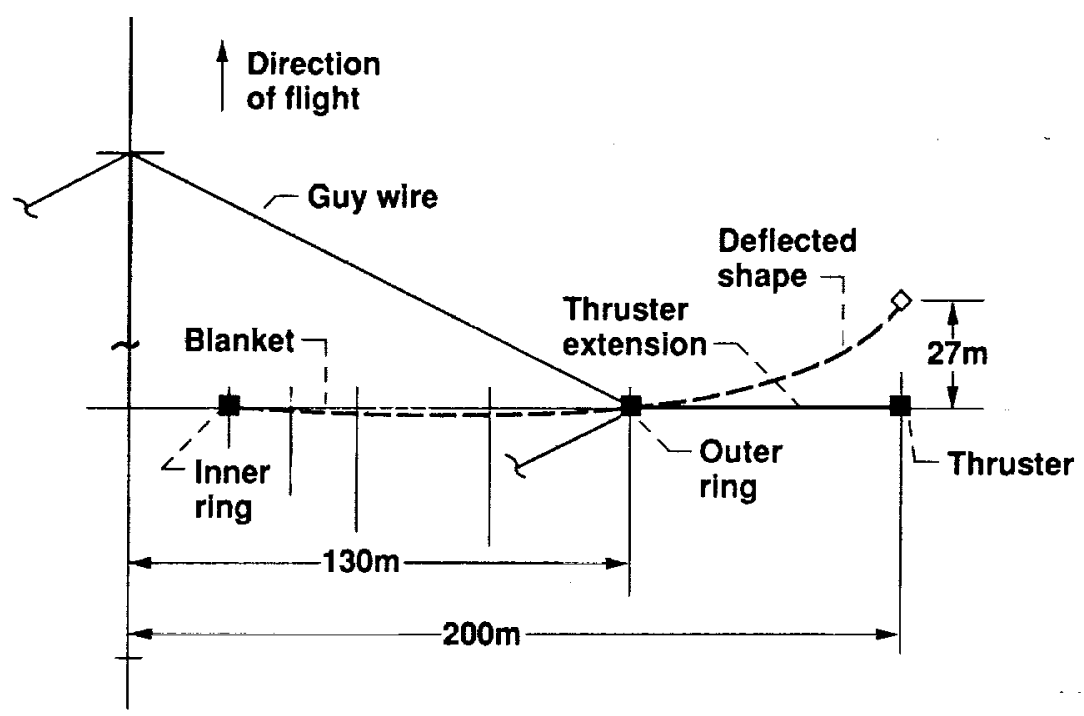

(a) Ring structure.

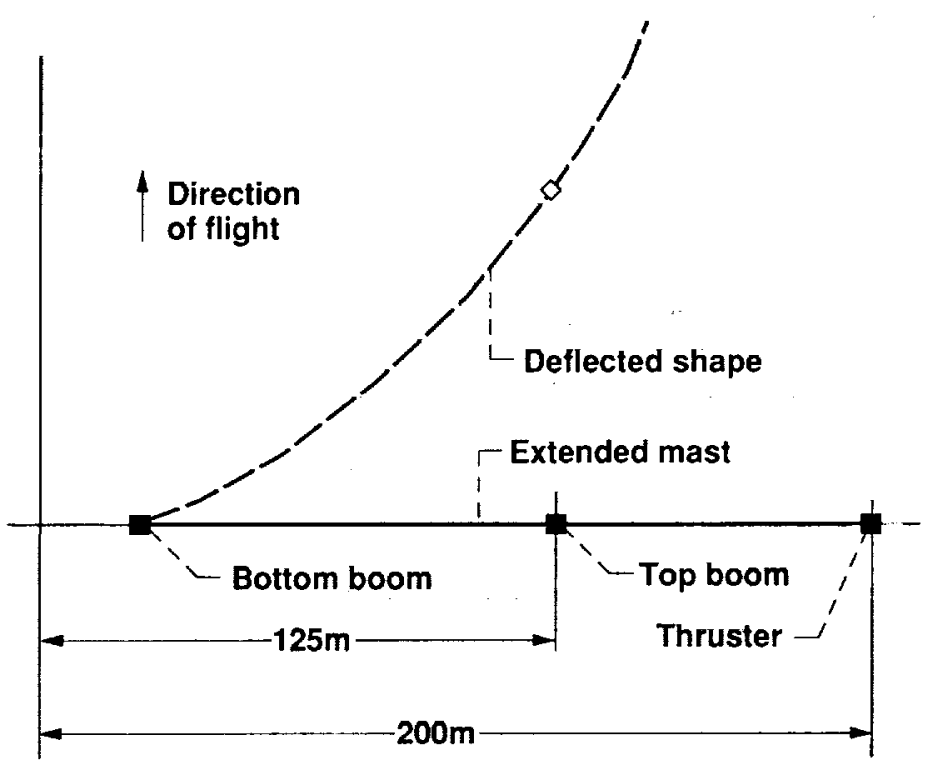

(b) Split blanket.

Figure 11.-Deflected shape resulting from thruster loadings. (Note: deflections drawn to scale). 
Public reporting burden for this colloction of Inlormation ls estimatod to average 1 hour per response, including the time for reviewing instructions, searching extating data sources, gathering and maintaining the dala needed, and completing and reviowing the collectlon of lnformation. Send commente regarding this burden eatimate or any other aspect of this

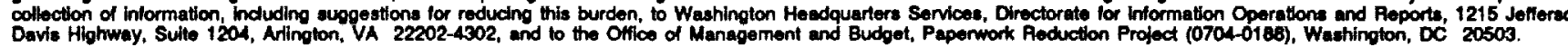
1. AGENCY USE ONLY (LeaVe blank)
2. REPORT DATE
August 1991
3. REPORT TYPE AND DATES COVERED
Technical Memorandum

4. TITLE AND SUBTITLE

Structural Design Concepts for a Multi-Megawatt Solar

Electric (SEP) Spacecraft

6. AUTHOR(8)

Charles Lawrence and J. Mark Hickman

None

5. FUNDINO NUMBERS

7. PERFormino ORgANization NAME(S) AND ADDRESS(ES)

National Aeronautics and Space Administration

Lewis Research Center

Cleveland, Ohio 44135-3191

9. SPONSORINGMONITORING AGENCY NAMES(S) AND ADDRESS(ES)

10. SPONSORINGMONTTORING AGENCY REPORT NUMBER

National Aeronautics and Space Administration

Washington, D.C. 20546-0001

NASA TM -105148

\section{SUPPLEMENTARY NOTE9}

Responsible person, Charles Lawrence, (216) 433- 6048.

12a. DISTRIBUTIONAVAILABILITY STATEMENT

12b. DISTAIBUTION CODE

Unclassified - Unlimited

Subject Category 39

13. ABSTRACT (Max/mum 200 words)

As a part of the Space Exploratory Initiative (SEI), NASA Lewis is investigating Solar Electric Propulsion (SEP) spacecraft to be used as a cargo transport vehicle to MARS. The purpose of the present study is to offer two preliminary structural design concepts for the SEP spacecraft; a split blanket array configuration, and a ring structure. The split blanket configuration is an expansion of the photovoltaic solar array design proposed for Space Station Freedom and consists of eight independent solar blankets stretched and supported from a central mast. The ring structural concept is a circular design with the solar blanket stretched inside a ring. This concept utilizes a central mast with guy wires to provide additional support to the ring. The two design concepts are presented, then compared by performing stability, normal modes, and forced response analyses for varying levels of blanket and guy wire preloads. The ring structure configuration is shown to be advantageous because it is much stiffer, more stable, and deflects less under loading than the split blanket concept.

\section{SUBJECT TERM8}

Large space structures; Dynamic structural analysis; Cargo spacecraft; Spacecraft structures

\begin{tabular}{|c|c|}
\hline 17. SECURITY CLASSIFICATION & 18. SECURITY CLASSIFICATION \\
OF REPORT & OF THIS PAQE \\
Unclassified & Unclassified
\end{tabular}

19. SECURITY CLASSIFICATION OF ABSTAACT Unclassified
15. NUMBER OF PAQES 18

16. PRICE CODE $\mathrm{AO} 3$

20. LIMITATION OF ABSTRACT 